\title{
The phylogeographic structure of Hydrilla verticillata (Hydrocharitaceae) in China and its implications for the biogeographic history of this worldwide-distributed submerged macrophyte
}

\author{
Jinning Zhu, Dan Yu* and Xinwei Xu
}

\begin{abstract}
Background: Aquatic vascular plants are a distinctive group, differing from terrestrial plants in their growth forms and habitats. Among the various aquatic plant life forms, the evolutionary processes of freshwater submerged species are most likely distinct due to their exclusive occurrence in the discrete and patchy aquatic habitats. Using the chloroplast trnL-F region sequence data, we investigated the phylogeographic structure of a submerged macrophyte, Hydrilla verticillata, the single species in the genus Hydrilla, throughout China, in addition to combined sample data from other countries to reveal the colonisation and diversification processes of this species throughout the world.

Results: We sequenced 681 individuals from 123 sampling locations throughout China and identified a significant phylogeographic structure $\left(\mathrm{N}_{S T}>\mathrm{G}_{\mathrm{ST}}, p<0.01\right)$, in which four distinct lineages occurred in different areas. A high level of genetic differentiation among populations ( $g$ lobal $F_{S T}=0.820$ ) was detected. The divergence of Hydrilla was estimated to have occurred in the late Miocene, and the diversification of various clades was dated to the Pleistocene epoch. Biogeographic analyses suggested an East Asian origin of Hydrilla and its subsequent dispersal throughout the world.

Conclusions: The presence of all four clades in China indicates that China is most likely the centre of Hydrilla genetic diversity. The worldwide distribution of Hydrilla is due to recent vicariance and dispersal events that occurred in different clades during the Pleistocene. Our findings also provide useful information for the management of invasive Hydrilla in North America.
\end{abstract}

Keywords: Biogeography, China, Hydrilla, Phylogeographic structure, Submerged macrophyte, trnL-F

\section{Background}

Aquatic vascular plants are a distinctive group, differing from terrestrial plants in their growth forms and habitats. They have multiple evolutionary origins from terrestrial environments and show a complex evolutionary history [1,2]. Many genera and species of aquatic plants are distributed worldwide [3,4]. Recently, the historical biogeographic scenarios of some genera, including their areas of origin and dispersal routes, have been inferred in the context of phylogenetics based on molecular evidence (e.g., [5-9]). However, the biogeographic history

\footnotetext{
*Correspondence: yudan01@public.wh.hb.cn; xuxw@whu.edu.cn National Field Station of Freshwater Ecosystem of Liangzi Lake, College of Life Sciences, Wuhan University, Wuhan, PR China
}

of cosmopolitan species of aquatic plants is seldom studied and needs to be explored through phylogeographic studies based on a broader sampling scheme.

An exponential growth of plant phylogeographic studies has been observed in Europe and North America in the past two decades, and a similar trend has recently been found in China and adjacent regions $[10,11]$. Common genetic discontinuities, locations of refuges, and routes of colonisation have been revealed in some regions by comparing phylogeographic structures among species [11-19]. In these plant phylogeographic studies, the majority of surveys were conducted on tree species and terrestrial plants, whereas studies on aquatic plants have been relatively scarce [10]. These studies on aquatic 
plants focused primarily on two groups: seagrasses (e.g., [20-22]) and emergent macrophytes in freshwater environments (e.g., [23-27]). Few studies have focused on freshwater submerged species (but see $[28,29]$ ), whose evolutionary processes are most likely distinct from those of emergent species due to their occurrence in exclusively aquatic habitats $[2,30]$, and seagrasses due to their lower population connectivity in discrete and patchy habitats [31]. Therefore, phylogeographic studies on freshwater submerged macrophytes will provide new insights to increase our understanding of plant evolution.

Here, we focus on the submerged plant genus Hydrilla, a monotypic genus of the family Hydrocharitaceae, which is distributed worldwide. The single Hydrilla species $H$. verticillata (L.f.) Royle (hydrilla) is found on all continents except Antarctica [32,33]. This species is native to Asia, but it is uncertain whether it is truly native to Europe, Australia and Africa. Hydrilla was first recorded in North America from 1960 and South America from 2005 $[4,32,34]$. Similar to most aquatic plants, hydrilla possesses a variety of reproductive strategies to ensure its growth and establishment, including reproduction through seeds, fragmentation, turions on leaf axils and tubers (subterranean turions) [35]. Hydrilla grows in various types of aquatic habitats (such as lakes, rivers and ponds) from tropical to temperate regions, and apparent morphological and karyological variations have been observed in different populations worldwide [32,36-40]. Monoecious and dioecious strains and diploid, triploid and tetraploid plants have also been reported in hydrilla [32,37]. Furthermore, high levels of genetic differentiation have been revealed among worldwide samples of hydrilla based on isoenzyme patterns [37,38], random amplified polymorphic DNA (RAPD) profiling [41,42], and DNA sequences [40,43]. However, previous investigations did not include a sufficient number of samples to explore the evolutionary processes of this submerged species worldwide.

In this study, we first examined the phylogeographic structure of an extensive sample population of hydrilla from China using sequences of the chloroplast trnL-F region. We then inferred the biogeographic history of hydrilla by combining the trnL-F sequences from previous studies conducted worldwide. Our objectives were (1) to examine the genealogical patterns of hydrilla in China, and (2) to infer the original area and dispersal route of hydrilla. This study will provide a good example for us to understand the evolutionary processes that occur in submerged macrophytes.

\section{Results}

Genetic variation and phylogeographic structure

A total of 681 sequences were obtained, with lengths ranging from 1,066 to $1,105 \mathrm{bp}$. The length of the aligned sequences was $1,130 \mathrm{bp}$, and 32 polymorphic sites were observed, including 18 indels and 14 base substitutions. The sequences were collapsed into 9 haplotypes (A1, A2, B1-B4, C1, C2, and D1). The two most common haplotypes were $\mathrm{C} 1$ (occurring 359 times; $52.7 \%$ ) and B1 (occurring 227 times; $33.3 \%$ ), which were present in 78 populations and 49 populations, respectively. Haplotypes D1, B4, A1, and B3 were detected in $11,6,5$ and 2 populations, respectively. The remaining three haplotypes, $\mathrm{A} 2, \mathrm{~B} 2$, and $\mathrm{C} 2$, were each present in a single population. Of the 123 populations we surveyed, 93 populations were monomorphic and consisted of a single haplotype. In the nine groups we defined based on river basins, the highest diversity was present in the Yangtze River Basin $(\mathrm{Hd}=0.625, \mathrm{Pi}=$ 0.0038 ) and the river basins in Southeast China ( $\mathrm{Hd}=$ $0.730, \mathrm{Pi}=0.0037$ ) (Additional file 1 ). However, no polymorphism was detected in the three river basins located in Northeast China and North China. The Hd and $\mathrm{Pi}$ values for all of the populations surveyed were 0.608 and 0.0038 , respectively (Additional file 1 ).

A haplotype network was constructed with four distinct groups based on all haplotypes from worldwide samples (see below for the definition of haplotypes) (Fig. 1b). The first group included four haplotypes (C1, $\mathrm{C} 2, \mathrm{H} 8$ and $\mathrm{H} 9$ ) and two Chinese haplotypes ( $\mathrm{C} 1$ and C2) involved all of the basins except for RB8 in South China, whereas the frequency of occurrence was low in the three basins (RB6, RB7, and RB9) located in the southern part of China. The second group only included one haplotype, D1, and was detected in two basins (RB4 and RB5). In RB5, the second group was restricted to the middle and lower reaches of the Yangtze River. The third group consisted of six haplotypes (B1-B4, H3 and H4), of which four Chinese haplotypes (B1-B4) occurred mostly south of the Yangtze River in five basins (RB5RB9). The fourth group comprised haplotypes A1, A2 and H7, of which two Chinese haplotypes (A1 and A2)were only found in six populations located in south and southeast China in four basins (RB5-RB8) (Fig. 1a). A permutation test showed that $\mathrm{N}_{\mathrm{ST}}(0.842)$ was significantly greater than $\mathrm{G}_{\mathrm{ST}}(0.799, \mathrm{P}<0.01)$, indicating that closely related haplotypes tended to occur in the same area. An AMOVA revealed that $17.97 \%$ of the total variation occurred within populations, and $82.03 \%$ occurred between populations. The global $\mathrm{F}_{\mathrm{ST}}$ value $(0.820)$ indicated a significant genetic structure among the 123 hydrilla populations. When we grouped the populations into basins, an AMOVA showed that large amounts of variation occurred both among the basins (40.09\%) and among the populations within basins (43.14 \%) and that $16.77 \%$ of the variation occurred within populations. The mismatch distribution of the overall populations was multimodal (not shown), and a sudden expansion model for hydrilla was therefore rejected. 


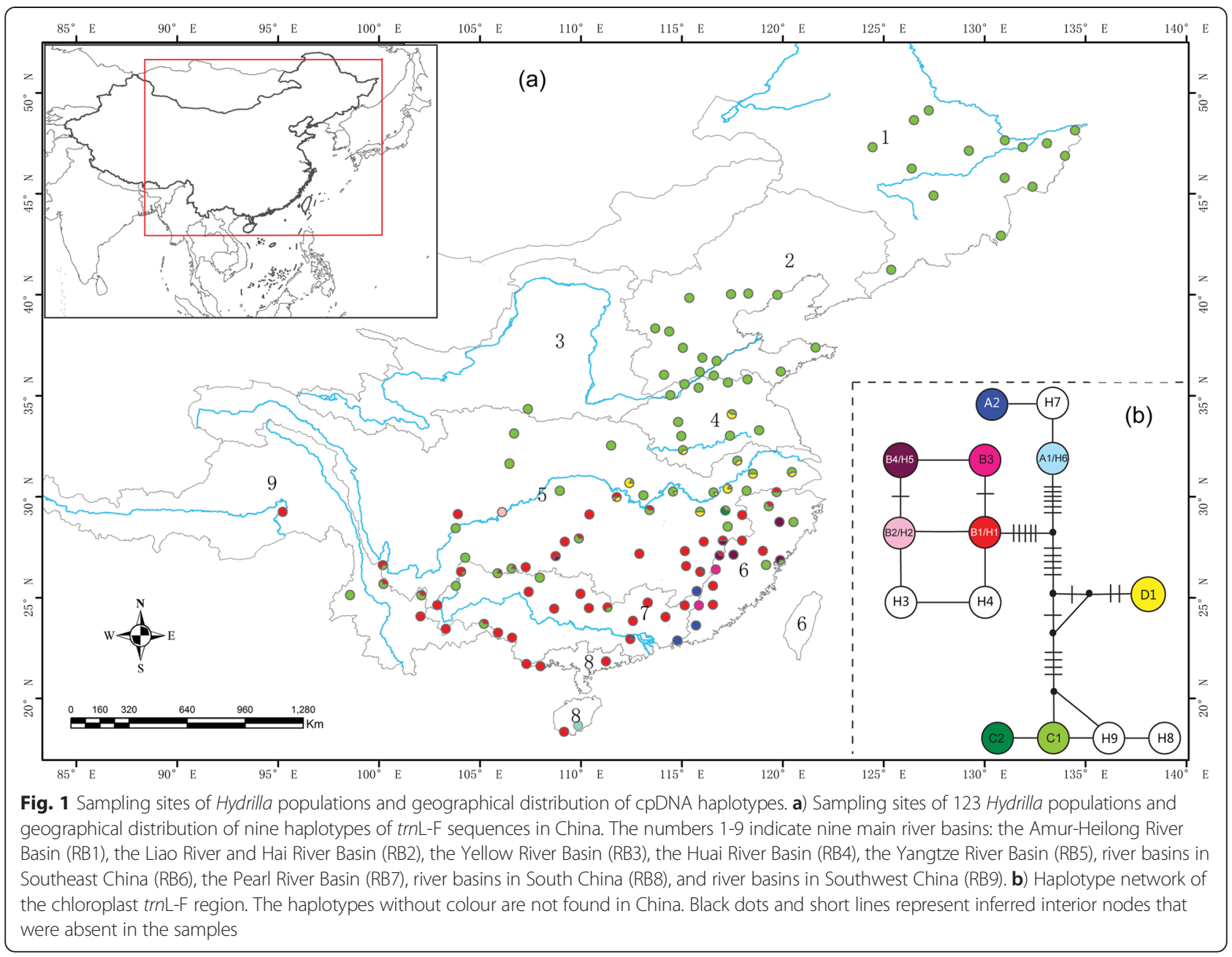

\section{Phylogenetic relationships}

The accessions collected from worldwide by Madeira $e t$ al. [43] were collapsed into 9 haplotypes: H1 (including samples from China, north Vietnam, Nepal, Pakistan, and India and dioecious US), H2 (Burundi), H3 (New Zealand), H4 (Australia), H5 (Korea and monoecious US), H6 (Thailand, Vietnam, and Taiwan), H7 (Indonesia, Malaysia, and Vietnam), H8 (Japan), and H9 (Poland). Four of the haplotypes were the same as haplotypes identified in our samples: $\mathrm{H} 1=\mathrm{B} 1, \mathrm{H} 2=\mathrm{B} 2, \mathrm{H} 5=\mathrm{B} 4$, and H6 = A1. Thus, a total of 14 haplotypes were obtained and employed for phylogenetic reconstruction using three outgroups. ML analysis and Bayesian inference produced a similar topology (Fig. 2). The monophyly of hydrilla was strongly supported by both analyses (bootstrap support $(\mathrm{BS})=100 \%$, posterior probability $(\mathrm{PP})=1.00)$. Four distinct clades with robust support were revealed among the 14 haplotypes of hydrilla, consistent with four groups of the haplotype network. Haplotypes of the A lineage (A1/ H6, A2, and H7) were located in south and Southeast China and Southeast Asia. B lineage haplotypes (B1/H1,
$\mathrm{B} 2 / \mathrm{H} 2, \mathrm{~B} 3, \mathrm{~B} 4 / \mathrm{H} 5, \mathrm{H} 3$, and $\mathrm{H} 4)$ were present in Korea, south of the Yangtze River in China, South Asia, Burundi, Australia and North America. The A and B lineages grouped into a clade with high support values (BS $=88 \%$, $\mathrm{PP}=1.00)$. $\mathrm{C}$ lineage haplotypes $(\mathrm{C} 1, \mathrm{C} 2, \mathrm{H} 8$ and $\mathrm{H} 9)$ were found in most areas of China, Japan and Poland. The D lineage haplotype (D1) was present only in China, showing a narrow range (Figs. 1a and 2).

\section{Divergence time estimates}

The stem and crown ages of hydrilla were estimated to be $36.19 \mathrm{Ma}$ (95 \% HPD: 33.74-40.93 Ma) and 6.71 Ma $(0.12-22.42 \mathrm{Ma})$, respectively, based on the combined data (Fig. 3). Due to no bootstrap support for the internal nodes of hydrilla in the multigene tree, which was caused by low polymorphism (Additional file 2), the trnL-F sequences were used to estimate interior divergence times. The crown age of clade $\mathrm{A}+\mathrm{B}$ was estimated to be $4.57 \mathrm{Ma}(95 \% \mathrm{HPD}=2.06-7.15 \mathrm{Ma})$ based on the trnL-F sequence data (Fig. 2). The crown node ages of clades A, B and C were dated to $1.31 \mathrm{Ma}(95 \%$ 


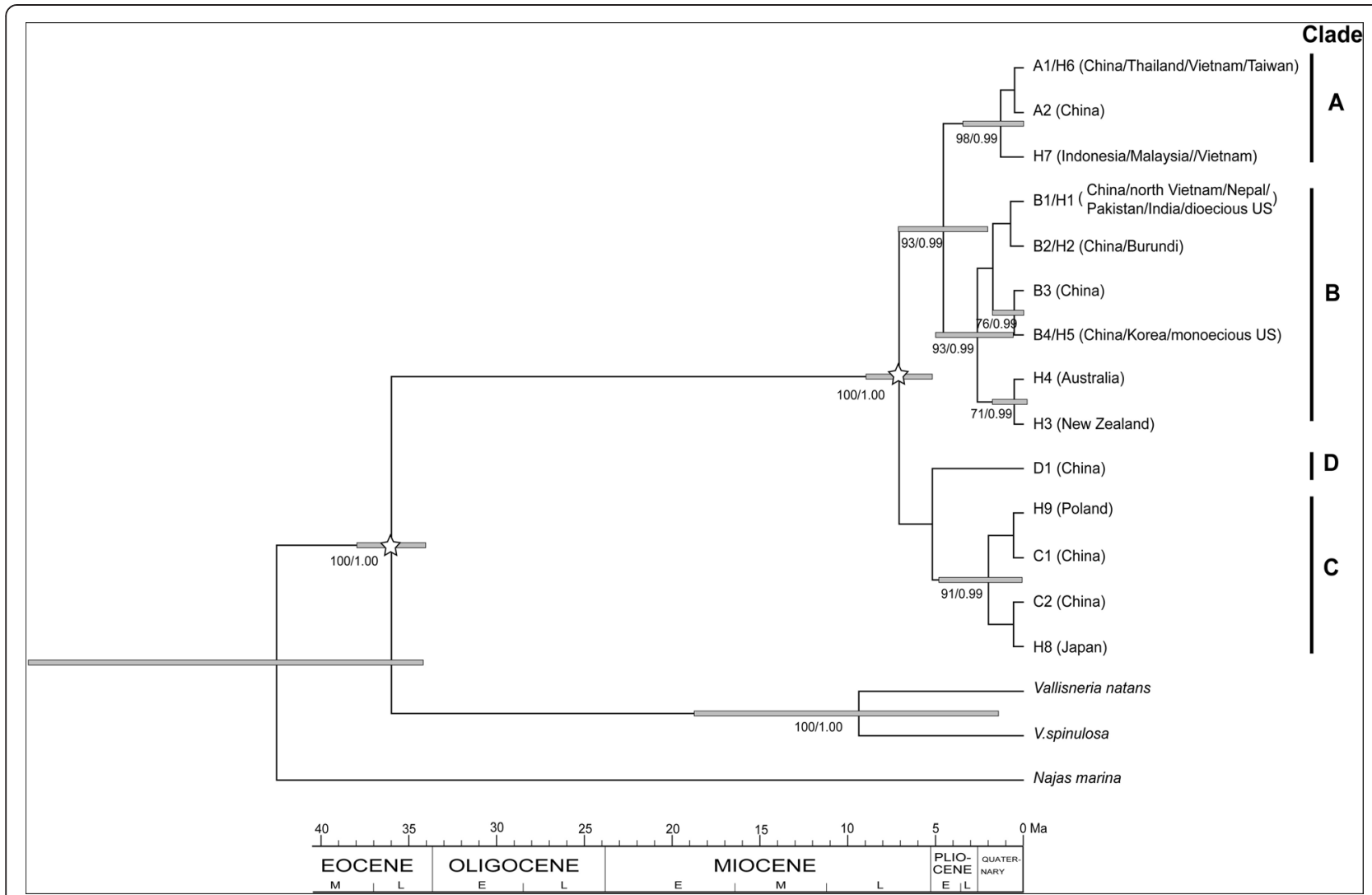

Fig. 2 Chronogram of Hydrilla inferred from trnL-F sequences using BEAST. Two clade constraints are indicated with blank asterisks. Grey boxes indicate the $95 \%$ highest posterior density intervals. The maximum likelihood bootstrap values of 70 and above (left) and the posterior probabilities of 0.95 and above (right) are shown at the nodes

HPD: $0.01-3.45 \mathrm{Ma}), 2.63 \mathrm{Ma}(0.59-4.99 \mathrm{Ma})$ and 2.00 Ma (0.09-4.79 Ma), respectively (Fig. 2).

\section{Historical biogeography inference}

The S-DIVA, BBM and DEC analyses conducted with different numbers of maximum area settings obtained similar biogeographic inferences, with the exception of several nodes, and only the results for the 4 maximum areas are presented. The S-DIVA, BBM and DEC analyses all suggested that the ancestral area of hydrilla at node 28 was East Asia with the highest likelihood. For the ancestral range of interior node 23 of clade $\mathrm{A}+\mathrm{B}$ and node 26 of clade C, East Asia was supported by all three analyses with the highest likelihood. At node 17 of clade A and node 22 of clade B, East Asia was supported as the ancestral range by BBM, whereas East Asia plus Southeast Asia and East Asia plus Oceania were inferred by S-DIVA and DEC, respectively (Fig. 4). Dispersal and vicariant events were also revealed. All the three analyses postulated vicariant events at nodes 17, 22 and 25. The dispersal events were detected at nodes 16, 18, 23, 26 in S-DIVA analysis, at nodes 16, 17, 22, 25 in BBM analysis and at nodes 16, 17, 18, 23, 26 in DEC analysis.

\section{Discussion}

\section{Genetic variation in hydrilla}

At the population level, more than three-fourths of the populations are composed of only a single haplotype. Although the percentage may be overestimated due to limited samples of each population and a single cpDNA fragment used, lack of intra-population variation seems frequent. This is most likely attributed to the strong ability of hydrilla to reproduce asexually. Hydrilla populations can expand rapidly via various vegetative propagules, including plant fragmentation, turions and tubers [44-46]. As vegetative reproduction is common in aquatic plants, modest variations within populations have also been observed in other species, e.g., Ranunculus bungei [29], Podostemum ceratophyllum [47], and Hippuris vulgaris [48]. Moreover, certain studies based on nuclear markers suggested that founder effects played an important role in the establishment of populations in aquatic plants $[26,49,50]$. To explore the role of founder effects in shaping population structure of hydrilla, further studies using nuclear markers are needed.

This study suggests that China is most likely the central area of genetic diversity for hydrilla. Both Madeira et al. 


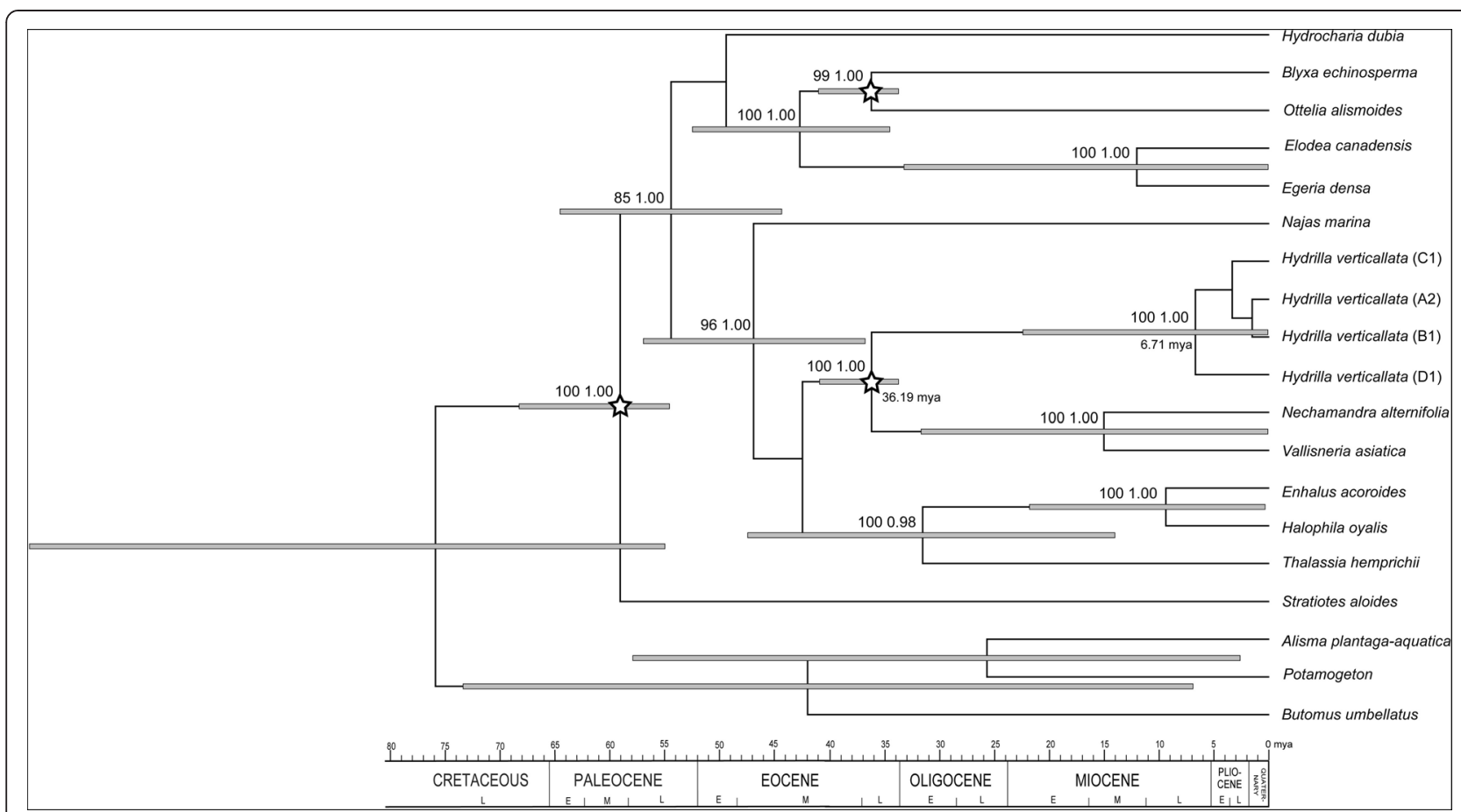

Fig. 3 Chronogram of Hydrocharitaceae inferred from combined $18 \mathrm{~S}+r b c \mathrm{~L}+$ matK $+\operatorname{trnK} 5^{\prime}$ intron $+r p o B+r p o C 1+c o b+a t p 1$ sequence data using BEAST. Three calibration points are indicated with blank asterisks. Grey boxes indicate $95 \%$ highest posterior density intervals. The maximum likelihood bootstrap values of 70 and above (left) and the posterior probabilities of 0.95 and above (right) are shown at the nodes

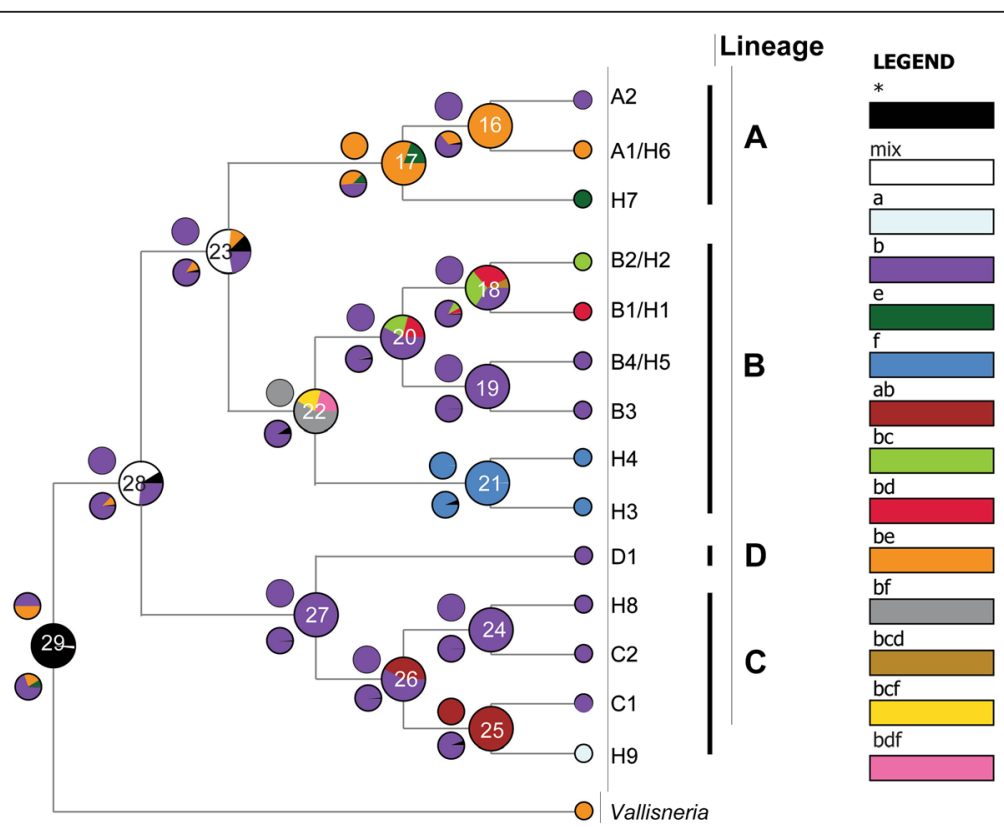

Fig. 4 Reconstruction of the ancestral area of Hydrilla. The pie charts at each node were obtained using DEC analysis, and the smaller pie charts above and below each node were obtained through S-DIVA and BBM analysis, respectively. The colours correspond to possible ancestral areas; black with an asterisk represents other ancestral ranges; and white with "mix" indicates too many possible ancestral areas to determine. Lowercase letters represent different regions: a) Europe (Poland); b) East Asia (China/Korea/Japan); c) Africa (Burundi); d) South Asia (India/Nepal); e) Southeast Asia (Vietnam/ Thailand/Malaysia/Indonesia); f) Oceania (Australia/New Zealand) 
[43] and Benoit [40] identified three clades from worldwide samples of hydrilla based on chloroplast trnL-F sequences, corresponding closely to those identified by Madeira et al. [41,42] using RAPD. As China is the geographic centre of the distribution range of hydrilla, the small number of accessions from China (less than 5 individuals) included in these studies is insufficient. Combined with the trnL-F sequences of samples obtained worldwide, our results revealed four clades in hydrilla, and China was the only area in which haplotypes from all four clades occurred (Fig. 2). Furthermore, a low level of genetic variation was observed in hydrilla samples from other areas, e.g., in Europe, nearly identical isoenzyme patterns were observed in plants from Ireland and Poland [51] and the same trnL-F sequences were present in plants from Ireland and Latvia [40]; in Africa, similar isoenzyme patterns or genetic types were revealed in plants from Uganda, Rwanda and Burundi [38,52]; in South Asia, samples from Nepal, Pakistan and India grouped into the same cluster according to random amplified polymorphic DNA (RAPD) analysis [41] and exhibited the same trnL-F sequences [43]; in Southeast Asia, individuals from Vietnam, Thailand, Malaysia and Indonesia grouped into the same cluster according to RAPD analysis [42] and included two clades of trnL-F sequences [43], Fig. 2; and in Australia, samples from five localities included two clades of $t r n \mathrm{~L}-\mathrm{F}$ sequences [40]. Based on 109 samples from various areas in Asia and the Indo-Pacific region, the highest genetic diversity was found in China with microsatellite markers [52]. Therefore, the highest genetic diversity of hydrilla was most likely detected in populations from China.

\section{Phylogeographic structure of hydrilla}

An important characteristic of hydrilla is the high value of global $\mathrm{F}_{\mathrm{ST}}(0.820)$, indicating that most genetic variation is found among populations. The results of an AMOVA suggested that half of the detected genetic variations should be ascribed to genetic differentiation among the basins. This finding was supported by the significant phylogeographic structure revealed, in which the haplotypes of lineage $\mathrm{C}$ mostly occurred in the northern part of China, lineage B occurred in the southern part of China, lineage D haplotype was restricted to the Huai River and the middle and lower reaches of the Yangtze River, and lineage A was restricted to the southeast corner of China (Fig. 1). According to the distribution of haplotypes in basins, the isolation of individual basins appears to constitute a barrier to inter-basin gene flow. High genetic differentiation among basins was also reported in some species of aquatic plants, e.g., Batrachium bungei [49], Podostemum irgangii [53], and Podostemum ceratophyllum [47]. However, unlike these species, hydrilla can form tubers, which may survive for several days after removal from water [54] and remain viable even after ingestion and regurgitation by waterfowl [55]. It is possible that waterfowl migration could transport viable tubers across water basins. The high genetic differentiation of hydrilla populations observed among basins may be attributed to other factors associated with the process of colonisation. Two phylogeographic studies on aquatic plants with extensive sampling have been conducted in China (Zizania latifolia [26] and Sagittaria trifolia [25]). Similarly, no significant phylogeographic structure was revealed in these two species, and the highest diversity was reported from Northeast China, a finding that is different from hydrilla's pattern. Because the two species are emergent and their evolutionary processes are likely to differ significantly from submerged groups [2], it is necessary to conduct comparative phylogeographic studies focusing on submerged macrophytes.

\section{Biogeographic history of hydrilla}

The divergence time estimates for hydrilla showed a remarkably long branch between the stem node of this genus in the late Eocene and its crown node in the late Miocene (Figs. 2 and 3), suggesting long-term stasis or extinct lineages before diversification in hydrilla, similar to what has been found in several other genera of Hydrocharitaceae, such as Najas, Ottelia, and Blyxa [9]. The East Asian origin of hydrilla inferred through ancestral area reconstruction is supported by the fact that China is most likely the centre of genetic diversity for this genus. The first diversification of hydrilla into three lineages (clade $\mathrm{A}+\mathrm{B}$, clade $\mathrm{C}$ and clade $\mathrm{D}$ ) was dated to the late Miocene (Fig. 3) and may have been triggered by the existence of warm-cool alternations and a cold, dry climate due to strengthened East Asian winter monsoons during the late Miocene and Pliocene [56-59]. Clade A + B dispersed from East Asia to other areas and then diverged into clades $\mathrm{A}$ and $\mathrm{B}$ during the early Pliocene (Fig. 2). The diversification events for clades A, B and $\mathrm{C}$ were all dated to the Pleistocene epoch, associated with Quaternary glacial/interglacial cycles. Due to the interior divergence times in hydrilla were estimated by the trnL-F sequences despite its high polymorphism (Additional file 2), their accuracy needed to be further tested by more sequence data.

The three analyses (S-DIVA, BBM and DEC) inferred vicariance at nodes 17,22 and 25 , of which node 17 is the crown node of clade A and 22 is the crown node of clade $B$ with robust support (Fig. 2), indicating a vicariant event during the diversification in clade A and in clade B. The crown ages of both clades were dated to the Pleistocene epoch, in which cool glacial periods and warm interglacial periods were alternative. Climate change could be responsible for the vicariant events (e.g., [27]). For example, in clade A East Asian populations could have been isolated 
from Southeast Asian ones during more than one glacial period due to the emergence or disappearance of large land areas between these two areas caused by great sea level fluctuation [60]. The S-DIVA, BBM and DEC analyses inferred dispersal events at different nodes except node 16. Most dispersal events were relatively recent, suggesting that waterfowl dispersals are likely given transoceanic distribution. Waterfowl are considered the most significant dispersal agents for aquatic plants [61,62]. Although the ability of seeds to maintain viability after passing through the gut has been reported in some groups of submerged macrophytes, such as Potamogeton and Najas $[63,64]$, whether hydrilla seeds can survive digestion by waterfowl has not been tested thus far. Some dispersal events, e.g., from East Asia to Southeast Asia in clade A and from East Asia to South Asia in clade B, are coincident with two major flyways for Anatidae in Asia [65], indicating the role of waterfowl in hydrilla distribution.

\section{Implications for the invasion of hydrilla}

Introducing the natural enemies of weeds into their native range is an effective way to control invasive weeds. Thus, it is important to pinpoint the likely origin of invasive weeds. Two biotypes of hydrilla (dioecious and monoecious) have been recognised in the United States [32]. These biotypes are thought to have been separately introduced $[35,66]$. The dioecious plants were reported to have been introduced from Sri Lanka to Florida [67], and the South Asian geographic origin of the US dioecious hydrilla was confirmed in genetic studies $[40,41,43]$. The occurrence of the common haplotype B1/H1 in China (Figs. 1a and 2) indicates that the southern part of East Asia is also a possible original site for the US dioecious hydrilla. The monoecious plants found in the US were possibly introduced from Korea based on genetic similarity $[41,43]$. The occurrence of the common haplotype B4/H5 in eastern China (Figs. 1a and 2) suggests eastern China as one of the original areas for the US monoecious hydrilla. Due to the independent origin of the two biotypes of hydrilla, the search for natural enemies of hydrilla needs to be conducted in each original range, especially in the common area of China.

The northernmost monoecious hydrilla population occurs in the Lucerne/Pipe Lakes complex in Washington, at $47.37^{\circ}$ north latitude [66]. The northernmost dioecious hydrilla population was found in Idaho but lacks detailed location information; it is most likely located at approximately $42^{\circ}$ north latitude [40]. The two biotypes both belong to clade B in the phylogenetic tree (Fig. 2). In their native range, the hydrilla populations belonging to clade $\mathrm{C}$ occur farther north than the populations belonging to clade B (Fig. 1a). The northernmost population we collected occurs at $49.12^{\circ}$ north latitude, a latitude similar to that of the US-Canada border. Based on their latitudinal distribution, hydrilla plants from clade $\mathrm{C}$ could easily occur in the border area between the US and Canada. Thus, importing hydrilla from the northern part of East Asia and Europe should be forbidden to avoid a new invasion of hydrilla into North America.

\section{Conclusions}

Our study reveals that China is most likely the centre of genetic diversity in Hydrilla, and our findings point to an East Asian origin of Hydrilla. The study provides empirical evidence, based on a phylogeographic analysis, that reveals the complex biogeographic history of diversification and colonisation in worldwide species of submerged macrophytes. Our results will be more persuasive once more extensive samples from other countries are included. Comparative studies on other submerged macrophytes that are distributed worldwide would be valuable in better understanding the diversification and colonisation of this distinct group of plants.

\section{Methods \\ Plant materials}

A total of 681 individuals of hydrilla were collected at 123 sites throughout its distribution range in China, from the northeast to the southwest (Fig. 1a, Additional file 1). Three to 12 shoots per population were randomly sampled from different individuals at intervals of at least $10 \mathrm{~m}$. Young, healthy plant fragments of approximately $10 \mathrm{~cm}$ in length were collected and dried with silica gel for subsequent DNA extraction. Voucher specimens from each population were deposited in the herbarium of Wuhan University (WH).

\section{DNA extraction, amplification and sequencing}

Total genomic DNA was extracted from silica-dried plant fragments using the DNA Secure Plant Kit (Tiangen Biotech, Beijing, China). Primers "c" and "f" reported by Taberlet et al. [68] were used to amplify and sequence the chloroplast trnL-F region. Polymerase chain reaction (PCR) was performed using 10-30 ng of genomic DNA, $0.1 \mu \mathrm{M}$ each primer, $0.2 \mathrm{mM}$ each dNTP, $2 \mathrm{mM} \mathrm{MgCl}$, and $0.6 \mathrm{U}$ of ExTaq DNA polymerase (TaKaRa) in a volume of $25 \mu \mathrm{L}$ under the following conditions: $3 \mathrm{~min}$ at $95^{\circ} \mathrm{C}$, followed by 35 cycles of $30 \mathrm{~s}$ at $95^{\circ} \mathrm{C}, 30 \mathrm{~s}$ at $55^{\circ} \mathrm{C}$, and $90 \mathrm{~s}$ at $72{ }^{\circ} \mathrm{C}$, and then a final $5 \mathrm{~min}$ extension at $72{ }^{\circ} \mathrm{C}$. Amplifications were conducted in a Veriti 96Well Thermal Cycler (Applied Biosystems, Foster City, USA). The PCR products were purified and sequenced in both directions by the Beijing Genomic Institute in Wuhan, China. All sequences of different haplotypes were deposited in GenBank (Accession Nos. KM982392KM982400). 


\section{Phylogeographic analyses}

Sequences were aligned using the program Mafft 6.7 [69], and manual adjustment was performed in Se-Al 2.0 [70]. The number of haplotypes $(\mathrm{H})$ and polymorphic sites (S), haplotype diversity (Hd), and nucleotide diversity $(\mathrm{Pi})$ were calculated using DNASP 5.10 [71]. To interpret the genealogical relationships among sequences, a median-joining network [72] based on haplotypes was generated from the cpDNA sequence data using NETWORK 4.5.1.6 (http://www.fluxus-engineering.com). In the network analysis, gaps with two or more base pairs were coded as single mutation events. When overlapping indels occurred, the overlap portion was considered a single event [73].

We defined groups of 123 populations of hydrilla based on basin boundaries. Nine groups were defined from the northeast to the southwest, corresponding to nine main basins: the Amur-Heilong River Basin (RB1), the Liao River and Hai River Basin (RB2), the Yellow River Basin (RB3), the Huai River Basin (RB4), the Yangtze River Basin (RB5), river basins in Southeast China (RB6), the Pearl River Basin (RB7), river basins in South China (RB8), and river basins in Southwest China (RB9) (Fig. 1a). An analysis of molecular variance (AMOVA) was used to partition genetic variation among and within groups, as implemented in ARLEQUIN 3.1 [74]. The occurrence of significant phylogeographic structure was tested by comparing two measures of population differentiation, $G_{S T}$ and $\mathrm{N}_{\mathrm{ST}}$, based on 1,000 permutations in PERMUT.

We examined pairwise mismatch distributions to detect historical demographic expansions using DNASP. Populations at demographic equilibrium should present a multimodal or random and rough distribution of pairwise differences, whereas populations experiencing a sudden demographic expansion are expected to display a unimodal and smooth distribution $[75,76]$.

\section{Biogeographic analyses}

We combined the sequences of 30 samples collected worldwide [43] into our dataset for phylogenetic analyses. Identical sequences were collapsed into a single haplotype. Based on phylogenetic studies of Hydrocharitaceae $[9,77,78]$, three closely related species, Vallisneria natans, $V$. spinulosa and Najas marina, were included as outgroups. We conducted maximum likelihood (ML) analysis in the program GARLI [79], beginning with random trees and using 10,000,000 generations per search. Bootstrap support was estimated from 1,000 bootstrap replicates in GARLI. Bayesian inference was implemented in MrBayes 3.1.2 [80]. Two independent Markov Chain Monte Carlo (MCMC) analysis runs were conducted simultaneously, beginning with a random tree, with each run including four chains (one cold and three hot). Two million generations were run, with sampling at every 1,000 generations. Tracer 1.4 [81] was employed to check whether the chains converged, and the first $25 \%$ of samples were discarded as burn-in. The best-fit model of nucleotide substitution for the ML and Bayesian analyses was identified under the Akaike information criterion (AIC) implemented in Modeltest 3.7 [82].

The divergence time between clades in hydrilla was estimated in two steps. First, we estimated the age of the stem and crown nodes of hydrilla based on combined $18 \mathrm{~S}+r b c \mathrm{~L}+$ mat $\mathrm{K}+\operatorname{trn} \mathrm{K} 5$ ' intron + rpo $\mathrm{B}+r p o \mathrm{C} 1+c o b$ + atp 1 sequence data from 12 genera within Hydrocharitaceae and three outgroups from Chen et al. [9]. We amplified and sequenced these eight fragments in four hydrilla individuals with haplotypes A2, B1, C1, and D1, representing four distinct lineages in the phylogenetic analysis (see results). All of the obtained sequences were deposited in GenBank (Accession Nos. KM982360KM982391) and combined into the dataset. Datasets for cpDNA and $18 \mathrm{~S}$ sequences were found to be combinable according to the incongruence length difference test [83] $(p>0.05)$. The divergence time estimate was conducted in BEAST 1.7.4 [84] using the dataset including 16 taxa. The parameter set and calibration points were the same as those used by Chen et al. [9]. Due to the combined dataset did not provide a topology that had nodal support within hydrilla (see Fig. 3), which was the same as any of these fragments (results not shown), we used the trnL-F sequences to infer the divergence time of internal nodes in hydrilla. Second, we employed the age of the stem and crown nodes of hydrilla to estimate interior divergence times in hydrilla based on the trnL-F sequences. We applied the GTR model of nucleotide substitution with Gamma Categories set to six under an uncorrelated lognormal relaxed clock model [85]. MCMC analyses of 300,000,000 generations were implemented, in which every 1,000 generations were sampled. The first $10 \%$ of generations were discarded as burn-in, and the parameters were checked using the program Tracer.

Based on the Bayesian framework, three analyses were used to reconstruct the possible ancestral ranges of hydrilla. A statistical dispersal-vicariance analysis (S-DIVA) and a Bayesian binary MCMC (BBM) were implemented in the program RASP (Reconstruct Ancestral State in Phylogenies, [86]). Another event-based method dispersalextinction cladogenesis (DEC) was implemented in the program LAGRANGE $2.0 .1[87,88]$. Six areas were defined according to the distribution range of hydrilla: a) Europe (Poland); b) East Asia (China/Korea/Japan); c) Africa (Burundi); d) South Asia (India/Nepal /Pakistan); e) Southeast Asia (Vietnam/Thailand/Malaysia/Indonesia); and f) Oceania (Australia/New Zealand). Only the most closely related genus Vallisneria was chosen as outgroup, and its ancestral area was restricted to East Asia and Southeast Asia according to the results of 
Chen et al.[9].The invaded region of North America was excluded from these analyses due to the human introduction of hydrilla to the continent. The number of maximum areas was set to range from 2-6. In the BBM analysis, a fixed JC + G (Jukes-Cantor + Gamma) model was chosen with a null root distribution. The MCMC chains were run for 5,000,000 generations, and every 100 generations were sampled. In the DEC analysis, the dispersal probability between areas was set to the same value.

\section{Availability of supporting data}

The data set supporting the results of this article is included within the article and its additional files. The 41 cpDNA sequences supporting the results of this article are available in the National Center for Biotechnology Information (GenBank) under accession numbers KM982360KM982400, http://www.ncbi.nlm.nih.gov/Genbank/.

\section{Additional files}

\section{Additional file 1: Collection sites and haplotype distribution of Hydrilla populations in China.}

Additional file 2: Information of variation in the combined $18 \mathrm{~S}+$ $r b c \mathrm{~L}+$ mat $\mathrm{K}+$ trnK $5^{\prime}$ intron $+r p o \mathrm{~B}+r p o \mathrm{C} 1+c o b+a t p 1$ sequence data and trnL-F sequence data for Hydrilla.

\section{Competing interests}

The authors declare that they have no competing interests.

\section{Authors' contributions}

XX and DY conceived the ideas; JZ collected the data; and JZ and XX analysed the data and led the writing. All authors read and approved the final manuscript.

\section{Acknowledgements \\ This study was supported by grants from the National Natural Science Foundation of China to Xinwei Xu (31070190 and 31270265) and Dan Yu (30930011). We thank the members of Dan Yu's group for their advice and field assistance. The basin data included in the map figures were provided by the Scientific Data Sharing Platform for Lakes and Watersheds.}

Received: 19 October 2014 Accepted: 15 May 2015

Published online: 24 May 2015

\section{References}

1. Cook CD. Aquatic plant book. Hague: SPB Academic Publishing; 1990.

2. Barrett SCH, Eckert CG, Husband BC. Evolutionary processes in aquatic plant populations. Aquat Bot. 1993:44:105-45.

3. Sculthorpe CD. Biology of aquatic vascular plants. London UK: Edward Arnold Ltd; 1967.

4. Cook CDK. Range extensions of aquatic vascular plant species. J Aquat Plant Manage. 1985;23:1-6.

5. Kimball RT, Crawford DJ, Les DH, Landolt E. Out of Africa: molecular phylogenetics and biogeography of Wolffiella (Lemnaceae). Biol J Linn Soc. 2003;79(4):565-76.

6. Vaughan DA, Ge S, Kaga A, Tomooka N. Phylogeny and biogeography of the genus Oryza. Rice Biology in the Genomics Era. 2008;62:219-34.

7. Xu XW, Walters C, Antolin MF, Alexander ML, Lutz S, Ge S, et al. Phylogeny and biogeography of the eastern Asian-North American disjunct wild-rice genus (Zizania L., Poaceae). Mol Phylogenet Evol. 2010;55(3):1008-17.
8. Chen LY, Chen JM, Gituru RW, Temam TD, Wang QF. Generic phylogeny and historical biogeography of Alismataceae, inferred from multiple DNA sequences. Mol Phylogenet Evol. 2012;63(2):407-16.

9. Chen LY, Chen JM, Gituru RW, Wang QF. Generic phylogeny, historical biogeography and character evolution of the cosmopolitan aquatic plant family Hydrocharitaceae. BMC Evol Biol. 2012;12(1):30-41.

10. Beheregaray LB. Twenty years of phylogeography: the state of the field and the challenges for the Southern Hemisphere. Mol Ecol. 2008;17(17):3754-74.

11. Qiu YX, Fu CX, Comes HP. Plant molecular phylogeography in China and adjacent regions: tracing the genetic imprints of Quaternary climate and environmental change in the world's most diverse temperate flora. Mol Phylogenet Evol. 2011;59(1):225-44.

12. Soltis DE, Gitzendanner MA, Strenge DD, Soltis PS. Chloroplast DNA intraspecific phylogeography of plants from the Pacific Northwest of North America. Plant Syst Evol. 1997;206(1-4):353-73.

13. Soltis DE, Morris AB, McLachlan JS, Manos PS, Soltis PS. Comparative phylogeography of unglaciated eastern North America. Mol Ecol. 2006;15(14):4261-93.

14. Taberlet P, Fumagalli L, Wust-Saucy AG, Cosson JF. Comparative phylogeography and postglacial colonization routes in Europe. Mol Ecol. 1998;7(4):453-64.

15. Petit RJ, Csaikl UM, Bordács S, Burg K, Coart E, Cottrell J, et al. Chloroplast DNA variation in European white oaks: phylogeography and patterns of diversity based on data from over 2600 populations. Forest Ecol Manag. 2002;156(1):5-26

16. Tribsch A, Schönswetter P. Patterns of endemism and comparative phylogeography confirm palaeoenvironmental evidence for Pleistocene refugia in the Eastern Alps. Taxon. 2003;52(3):477-97.

17. Carstens BC, Degenhardt JD, Stevenson AL, Sullivan J. Accounting for coalescent stochasticity in testing phylogeographical hypotheses: modelling Pleistocene population structure in the Idaho giant salamander Dicamptodon aterrimus. Mol Ecol. 2005;14(1):255-65.

18. Chiang TY, Schaal BA. Phylogeography of plants in Taiwan and the Ryukyu Archipelago. Taxon. 2006:55(1):31-41.

19. Fujii N, Senni K. Phylogeography of Japanese alpine plants: biogeographic importance of alpine region of Central Honshu in Japan. Taxon. 2006;55(1):43-52.

20. Olsen $J$, Stam WT, Coyer JA, Reusch TB, Billingham M, BOSTRÖM C, et al. North Atlantic phylogeography and large-scale population differentiation of the seagrass Zostera marina L. Mol Ecol. 2004;13(7):1923-41.

21. Hoarau G, Coyer JA, Veldsink JH, Stam WT, Olsen JL. Glacial refugia and recolonization pathways in the brown seaweed Fucus serratus. Mol Ecol. 2007;16(17):3606-16.

22. Neiva J, Pearson GA, Valero M, Serrao EA. Drifting fronds and drifting alleles: range dynamics, local dispersal and habitat isolation shape the population structure of the estuarine seaweed Fucus ceranoides. J Biogeogr. 2012;39(6):1167-78.

23. Eckert CG, Lui K, Bronson K, Corradini P, Bruneau A. Population genetic consequences of extreme variation in sexual and clonal reproduction in an aquatic plant. Mol Ecol. 2003;12(2):331-44.

24. Dorken ME, Barrett SCH. Phenotypic plasticity of vegetative and reproductive traits in monoecious and dioecious populations of Sagittaria latifolia (Alismataceae): a clonal aquatic plant. J Ecol. 2004;92(1):32-44.

25. Chen JM, Liu F, Wang QF. Phylogeography of a marsh herb Sagittaria trifolia (Alismataceae) in China inferred from cpDNA atpB-rbcL intergenic spacers. Mol Phylogenet Evol. 2008;48(1):168-75.

26. Xu XW, Ke WD, Yu XP, Wen J, Ge S. A preliminary study on population genetic structure and phylogeography of the wild and cultivated Zizania latifolia (Poaceae) based on Adh1a sequences. Theor Appl Genet. 2008;116(6):835-43.

27. Arrigo N, Buerki S, Sarr A, Guadagnuolo R, Kozlowski G. Phylogenetics and phylogeography of the monocot genus Baldellia (Alismataceae): Mediterranean refugia, suture zones and implications for conservation. Mo Phylogenet Evol. 2011;58(1):33-42.

28. Les DH, Peredo EL, Benoit LK, Tippery NP, King UM, Sheldon SP. Phytogeography of Najas gracillima (Hydrocharitaceae) in North America and its cryptic introduction to California. Am J Bot. 2013;100(9):1905-15.

29. Chen JM, Du ZY, Yuan YY, Wang QF. Phylogeography of an alpine aquatic herb Ranunculus bungei (Ranunculaceae) on the Qinghai-Tibet Plateau. J Syst Evol. 2014;52(3):313-25.

30. Les DH. Breeding systems, population structure, and evolution in hydrophilous angiosperms. Ann Mo Bot Gard. 1988;75:819-35. 
31. Nies G, Reusch T. Evolutionary divergence and possible incipient speciation in post-glacial populations of a cosmopolitan aquatic plant. J Evolution Biol. 2005;18(1):19-26

32. Cook CDK, Lüönd R. A revision of the genus Hydrilla (Hydrocharitaceae). Aquat Bot. 1982;13:485-504.

33. Sousa WTZ. Hydrilla verticillata (Hydrocharitaceae), a recent invader threatening Brazil's freshwater environments: a review of the extent of the problem. Hydrobiologia. 2011;669(1):1-20.

34. Sousa WTZ, Thomaz SM, Murphy KJ, Silveira MJ, Mormul RP. Environmental predictors of the occurrence of exotic Hydrilla verticillata (L.f.) Royle and native Egeria najas Planch. in a sub-tropical river floodplain: the Upper River Paraná, Brazil. Hydrobiologia. 2009;632(1):65-78.

35. Langeland KA. Hydrilla verticillata (L.f.) Royle (Hydrocharitaceae)," The Perfect Aquatic Weed". Castanea. 1996:61(3):293-304.

36. Chaudhuri JB, Sharma A. Cytological studies on three aquatic members of Hydrocharitaceae in relation to their morphological and ecological characteristics. Cytologia. 1978;43(1):1-19.

37. Verkleij JAC, Pieterse AH, Horneman GJ, Torenbeek M. A comparative study of the morphology and isoenzyme patterns of Hydrilla verticillata (L.f.) Royle. Aquat Bot. 1983;17(1):43-59.

38. Pieterse AH, Verkleij JAC, Staphorst HPM. A comparative study of isoenzyme patterns, morphology, and chromosome number of Hydrilla verticillata (L.f.) Royle in Africa. J Aquat Plant Manage. 1985;23:72-6.

39. Langeland KA, Laroche FB. Hydrilla growth and tuber production in response to bensulfuron methyl concentration and exposure time. J Aquat Plant Manage. 1992;30(2):53-8.

40. Benoit LK: Cryptic speciation, genetic diversity and herbicide resistance in the invasive aquatic plant Hydrilla verticillata (L.f.) Royle (Hydrocharitaceae): Dissertations collection for University of Connecticut; 2011.

41. Madeira PT, Van TK, Steward KK, Schnell RJ. Random amplified polymorphic DNA analysis of the phenetic relationships among world-wide accessions of Hydrilla verticillata. Aquat Bot. 1997;59(3):217-36.

42. Madeira PT, Van TK, Center TD. Integration of five Southeast Asian accessions into the world-wide phenetic relationships of Hydrilla verticillata as elucidated by random amplified polymorphic DNA analysis. Aquat Bot. 1999:63(2):161-7.

43. Madeira PT, Coetzee JA, Center TD, White EE, Tipping PW. The origin of Hydrilla verticillata recently discovered at a South African dam. Aquat Bot. 2007;87(2):176-80

44. Haller WT, Miller JL, Garrard LA. Seasonal production and germination of hydrilla vegetative propagules. J Aquat Plant Manage. 1976;14:26-9.

45. Langeland KA, Sutton DL. Regrowth of hydrilla from axillary buds. J Aquat Plant Manage. 1980;18:27-9.

46. Sutton DL, Van TK, Portier KM. Growth of dioecious and monoecious hydrilla from single tubers. J Aquat Plant Manage. 1992;30:15-20.

47. Fehrmann S, Philbrick CT, Halliburton R. Intraspecific variation in Podostemum ceratophyllum (Podostemaceae): evidence of refugia and colonization since the last glacial maximum. Am J Bot. 2012;99(1):145-51.

48. Chen JM, Du ZY, Sun SS, Gituru RW, Wang QF. Chloroplast DNA phylogeography reveals repeated range expansion in a widespread aquatic herb Hippuris vulgaris in the Qinghai-Tibetan Plateau and adjacent areas. PLoS one. 2013;8(4), e60948.

49. Wang YH, Chen JM, Xu C, Liu X, Wang QF, Motley TJ. Population genetic structure of an aquatic herb Batrachium bungei (Ranuculaceae) in the Hengduan Mountains of China. Aquat Bot. 2010;92(3):221-5.

50. Liao YY, Yue XL, Guo YH, Gituru WR, Wang QF, Chen JM. Genotypic diversity and genetic structure of populations of the distylous aquatic plant Nymphoides peltata (Menyanthaceae) in China. J Syst Evol. 2013;51(5):536-44.

51. Pieterse $A H$, Ebbers $A E H$, Verkleij JAC. A comparative study on isoenzyme patterns in Hydrilla verticillata (L.f.) royle from Ireland and North Eastern Poland. Aquat Bot. 1984;18(3):299-303.

52. Overholt WA, Copeland R, Williams D, Cuda J, Nzigidahera B, Nkubaye E, et al. Exploration for natural enemies of Hydrilla verticillata in East/Central Africa and genetic characterization of worldwide populations. In: Report to the Florida Department of Environmental Protection. Tallahassee: Bureau of Invasive Plant Management; 2008.

53. Baggio RA, Firkowski CR, Boeger MRT, Boeger WA. Differentiation within and between river basins of Podostemum irgangii (Podostemaceae), a rapid-water macrophyte of southern Brazil. Aquat Bot. 2013;107:33-8.
54. Basiouny FM, Haller WT, Garrard LA. Survival of hydrilla (Hydrilla verticillata) plants and propagules after removal from the aquatic habitat. Weed Sci. 1978;26:502-4

55. Joyce JC, Haller WT, Colle DE. Investigation of the presence and survivability of hydrilla propagules in waterfowl. Aquatics. 1980;2(3):10-1.

56. Guo ZT, Peng SZ, Hao QZ, Biscaye PE, An ZS, Liu TS. Late Miocene-Pliocene development of Asian aridification as recorded in the Red-Earth Formation in northern China. Global Planet Change. 2004:41(3):135-45.

57. Vandenberghe J, Lu H, Sun D, van Huissteden JK, Konert M. The late Miocene and Pliocene climate in East Asia as recorded by grain size and magnetic susceptibility of the Red Clay deposits (Chinese Loess Plateau). Palaeogeogr Palaeocl. 2004;204(3):239-55.

58. Fan MJ, Song CH, Dettman DL, Fang XM, Xu XH. Intensification of the Asian winter monsoon after 7.4 Ma: Grain-size evidence from the Linxia Basin, northeastern Tibetan Plateau, 13.1 Ma to 4.3 Ma. Earth Planet Sc Lett. 2006;248(1):186-97.

59. Wu NQ, Pei YP, Lu HY, Guo ZT, Li FJ, Liu TS. Marked ecological shifts during 6.2-2.4 Ma revealed by a terrestrial molluscan record from the Chinese Red Clay Formation and implication for palaeoclimatic evolution. Palaeogeogr Palaeocl. 2006;233(3):287-99.

60. Woodruff DS. Biogeography and conservation in Southeast Asia: how 2.7 million years of repeated environmental fluctuations affect today's patterns and the future of the remaining refugial-phase biodiversity. Biodivers Conserv. 2010;19(4):919-41

61. Santamaría L. Why are most aquatic plants widely distributed? Dispersal, clonal growth and small-scale heterogeneity in a stressful environment. Acta Oecol. 2002;23(3):137-54

62. Green AJ, Figuerola J, Sánchez MI. Implications of waterbird ecology for the dispersal of aquatic organisms. Acta Oecol. 2002;23(3):177-89.

63. Clausen P, Nolet BA, Fox A, Klaassen M. Long-distance endozoochorous dispersal of submerged macrophyte seeds by migratory waterbirds in northern Europe - a critical review of possibilities and limitations. Acta Oecol. 2002;23(3):191-203.

64. Figuerola J, Green AJ. Dispersal of aquatic organisms by waterbirds: a review of past research and priorities for future studies. Freshwater Biol. 2002:47(3):483-94

65. Miyabayashi Y, Mundkur T. Atlas of Key Sites for Anatidae in the East Asian Flyway. Tokyo Japan and Kuala Lumpur Asia Pacific: Wetlands International; 1999.

66. Madeira PT, Jacono CC, Van TK. Monitoring hydrilla using two RAPD procedures and the nonindigenous aquatic species database. J Aquat Plant Manage. 2000;38:33-40.

67. Schmitz DC. The invasion of exotic aquatic and wetland plants into Florida: history and efforts to prevent new introductions. Aquatics. 1990:12(2):6-24.

68. Taberlet P, Gielly L, Pautou G, Bouvet J. Universal primers for amplification of three non-coding regions of chloroplast DNA. Plant Mol Biol. 1991;17(5):1105-9.

69. Katoh $\mathrm{K}$, Toh $\mathrm{H}$. Recent developments in the MAFFT multiple sequence alignment program. Brief Bioinform. 2008;9(4):286-98.

70. Rambaut A: Se-Al v2. Oa11: sequence alignment editor. In:: Oxford, UK: University of Oxford. [http://tree.bio.ed.ac.uk/software/seal]

71. Librado P, Rozas J. DnaSP v5: a software for comprehensive analysis of DNA polymorphism data. Bioinformatics. 2009;25(11):1451-2.

72. Bandelt H-J, Forster $P$, Röhl A. Median-joining networks for inferring intraspecific phylogenies. Mol Biol Evol. 1999;16(1):37-48.

73. Golenberg EM, Clegg MT, Durbin ML, Doebley J, Ma DP. Evolution of a noncoding region of the chloroplast genome. Mol Phylogenet Evol. 1993;2(1):52-64.

74. Excoffier L, Laval G, Schneider S. Arlequin (version 3.0): an integrated software package for population genetics data analysis. Evol Bioinform Online. 2005;1:47-50.

75. Slatkin M, Hudson RR. Pairwise comparisons of mitochondrial DNA sequences in stable and exponentially growing populations. Genetics. 1991:129(2):555-62.

76. Rogers $A R$, Harpending $H$. Population growth makes waves in the distribution of pairwise genetic differences. Mol Biol Evol. 1992:9(3):552-69.

77. Tanaka N, Setoguchi H, Murata J. Phylogeny of the family Hydrocharitaceae inferred from rbcL and matK gene sequence data. J Plant Res. 1997;110(3):329-37. 
78. Les $\mathrm{DH}$, Moody ML, Soros CL. A reappraisal of phylogenetic relationships in the monocotyledon family Hydrocharitaceae (Alismatidae). Aliso. 2006;22:211-30.

79. Zwickl DJ: GARLI: genetic algorithm for rapid likelihood inference. [http:// www.bio.utexas.edu/faculty/antisense/garli/Garli.html]

80. Ronquist F, Huelsenbeck JP. MrBayes 3: Bayesian phylogenetic inference under mixed models. Bioinformatics. 2003;19(12):1572-4.

81. Rambaut A, Drummond A: Tracer. Version 1.3, MCMC Trace Analysis Tool. [http://tree.bio.ed.ac.uk/software/tracer/] Institute of Evolutionary Biology, University of Edinburgh; 2005.

82. Posada D, Crandall KA. Modeltest: testing the model of DNA substitution. Bioinformatics. 1998;14(9):817-8.

83. Farris JS, Källersjö M, Kluge AG, Bult C. Testing significance of incongruence. Cladistics. 1994;10(3):315-9.

84. Drummond AJ, Rambaut A. BEAST: Bayesian evolutionary analysis by sampling trees. BMC Evol Biol. 2007;7(1):214.

85. Drummond AJ, Ho SYW, Phillips MJ, Rambaut A. Relaxed phylogenetics and dating with confidence. PLOS Biol. 2006;4(5):699-710.

86. Yu Y, Harris AJ, He XJ: RASP (reconstruct ancestral state in phylogenies) 2.0 beta. [http://mnh.scu.edu.cn/soft/blog/RASP]

87. Ree RH, Moore BR, Webb CO, Donoghue MJ. A likelihood framework for inferring the evolution of geographic range on phylogenetic trees. Evolution. 2005;59(11):2299-311.

88. Ree RH, Smith SA. Maximum likelihood inference of geographic range evolution by dispersal, local extinction, and cladogenesis. Syst Biol. 2008;57(1):4-14

\section{Submit your next manuscript to BioMed Central and take full advantage of:}

- Convenient online submission

- Thorough peer review

- No space constraints or color figure charges

- Immediate publication on acceptance

- Inclusion in PubMed, CAS, Scopus and Google Scholar

- Research which is freely available for redistribution 